\title{
Carbon Storage through Concrete Block Carbonation Curing
}

\author{
Hilal El-Hassan and Yixin Shao
}

\begin{abstract}
The effect of initial curing on carbonation curing of lightweight concrete masonry units (CMU) was examined. Initial curing was performed from 4 to 18 hours at a relative humidity of $50 \%$ and temperature of $25^{\circ} \mathrm{C}$. Based on cement content, four-hour carbonation curing allowed concretes to uptake $22 \%$ to $24 \% \mathrm{CO}_{2}$ with initial curing and $8.5 \%$ without initial curing, while prolonged 4-day carbonation recorded an uptake of $35 \%$. Carbonation curing can replace steam curing in $\mathrm{CMU}$ production to accelerate hydration and recycle cement kiln $\mathrm{CO}_{2}$ in a beneficial manner.
\end{abstract}

Index Terms - Concrete masonry unit, curing, carbonation, carbon uptake.

\section{INTRODUCTION}

Concrete masonry units (CMU) have been widely used in building construction as load bearing and non-load-bearing walls. The North American market for concrete blocks and bricks is projected to increase to 4.3 billion units per year by 2014 [1].

In comparison to cast-in-place concrete, masonry block structures not only exhibit superior performance due to precast quality, but also represent a low environmental impact construction system. With reference to $1 \mathrm{~m}^{2}$ of solid concrete wall, a masonry wall using 200-mm CMU requires $48 \%$ less material due to internal cavities, leading to $65 \%$ less cement, and $65 \%$ less $\mathrm{CO}_{2}$ emission.

CMUs produced in North America are typically steam cured. While steam curing accelerates strength gain and shortens the production cycles, the process itself is energy intensive. It is estimated, for one cubic meter of concrete in block form, atmospheric pressure steam curing consumes 0.59 Gigajoules per $\mathrm{m}^{3}$ of concrete and autoclave curing consumes 0.71 Gigajoules per $\mathrm{m}^{3}$ of concrete [2].

The alternative curing method for CMU production is carbonation curing which uses high purity carbon dioxide $\left(99.5 \%\right.$ of $\left.\mathrm{CO}_{2}\right)$ or low purity flue gas $\left(14 \%\right.$ of $\left.\mathrm{CO}_{2}\right)$ for accelerated hydration and durability improvement.

However, carbonation curing has never been adopted in large-scale production. This was possibly because flue gas carbonation was not effective in hydration acceleration and

Manuscript received June 10, 2013; revised July 23, 2013. This work was supported by the Natural Science and Engineering Research Council (NSERC) of Canada and Canadian Concrete Masonry Producers Association (CCMPA), and the supply of expanded slag aggregates by Lafarge Canada.

Hilal El-Hassan is with the Dept. of Civil Engineering at the American University in Dubai, Dubai Media City, Dubai, UAE, and P.O. BOX 28282 (email: helhassan@aud.edu).

Yixin Shao is with the Dept. of Civil Engineering and Applied Mechanics at McGill University, Montreal, Quebec, Canada, H3A 2K6 (email: yixin.shao@mcgill.ca). pure gas carbonation was expensive. The latter situation may change in the near future. Large quantities of high purity, low cost carbon dioxide could soon be available as regulations requiring reductions in $\mathrm{CO}_{2}$ emissions are developed. In this case, pure gas carbonation can simultaneously accelerate the strength, stabilize the dimension, and enhance the durability. By reducing the hydroxyl ion and precipitating $\mathrm{CaCO}_{3}$ on the surface layer, carbonation curing could improve the concrete resistance to sulfate attack, freeze-thaw cycling, and acid attack [3]. Since carbonation is a $\mathrm{CO}_{2}$ uptake process [4], recovered cement kiln $\mathrm{CO}_{2}$ can be recycled into concrete products to make contribution to carbon emission reduction.

The purpose of this research is to develop a carbonation curing process that can be used to replace steam curing for $\mathrm{CMU}$ production. High purity $\mathrm{CO}_{2}(99.5 \%)$ will be used to simulate the recovered cement kiln flue gas carbon dioxide. The goal is to shorten the carbonation duration to 2 to 4 hours with the help of initial curing ranging from 0 to 18 hours. The effect of initial curing on degree of carbonation reaction is evaluated to promote maximum possible carbon uptake in CMU. The carbon uptake is estimated using mass gain and thermal analysis.

\section{EXPERIMENTAL INVESTIGATIONS}

\section{A. Sample Preparation}

The carbonation curing parameters will be studied using rectangular slab concrete samples of $38 \mathrm{~mm}$ thickness to simulate the typical web or face shell of a hollow concrete masonry unit (CMU). The optimized process parameters are then applied to carbonation curing of 200-mm CMU. The samples are prepared according to the commercial CMU mix design with lightweight expanded slag aggregates. The as-received aggregates are nearly saturated with a water content of 5\%. Table I summarizes the mixture proportion of both slab and CMU samples. By mass, it includes a water-to-cement ratio of 0.4 , an aggregate-to-cement ratio of 6.23 , and cement content of 0.13 . Each rectangular slab sample weighs approximately 680 grams with a density of $1850 \mathrm{~kg} / \mathrm{m}^{3}$ and each CMU block weighs $15 \mathrm{~kg}$ with a density of $1839 \mathrm{~kg} / \mathrm{m}^{3}$. For rectangular slabs, raw materials were mixed in a pan mixer, cast into a $127 \times 76 \times 38 \mathrm{~mm}$ mold and compact formed using a vibrating hammer to simulate the industry production of CMU.

Because of the dry mix, concrete was demolded right after casting for initial curing. For 200-mm CMU blocks, materials were mixed in a mechanical drum mixer and compact formed by a manual block machine. They were typical 200-mm CMU blocks with the thickness of the web or face shell ranging from 25 to $33 \mathrm{~mm}$. The density was 
calculated based on ASTM C140 [5].

\begin{tabular}{|c|c|c|c|c|}
\multicolumn{5}{|c}{ TABLE I: MIXTURE PROPORTIONS } \\
\hline Slab $(\mathrm{g})$ & CMU $(\mathrm{g})$ & Mass $\left(\mathrm{kg} / \mathrm{m}^{3}\right)$ & Percent $(\%)$ \\
\hline Cement & 88 & 1967 & 241 & 13 \\
\hline Water & 35 & 787 & 96 & 5 \\
\hline Expanded Slag & 554 & 12251 & 1502 & 82 \\
\hline Sample & 677 & 15004 & 1839 & 100 \\
\hline
\end{tabular}

\section{B. Curing Procedures}

Curing procedures of different batches using rectangular slab samples are summarized in Table II. For comparison, Batches 1-4 are steam cured and Batches 5-15 are carbonation cured. One set of slab batches were also prepared for normal hydration in sealed plastic bag to serve as control. Steam curing took place in a steam cooker for a period of 4 hours with maximum temperature of $80^{\circ} \mathrm{C}$ and relative humidity of $95 \%$. Initial curing of $0,4,6$, and 8 hours at $22^{\circ} \mathrm{C}$ and relative humidity of $80 \%$ was applied prior to steam. Carbonation curing setup is shown in Fig. 1. Initial curing was performed on fresh concrete by $0,4,6,8$, and 18 hours respectively in an environmental chamber at a relative humidity of $50 \%$ and a temperature of $25^{\circ} \mathrm{C}$. The purpose of initial curing was to reduce the free water on the surface and allow diffusion of carbon dioxide. Initial curing of 0 hour was actually immediate carbonation of fresh concrete and served as reference. Initial curing of 18 hours was to simulate an overnight curing and was likely the longest preset that can be accepted by commercial production. Concrete slab samples after initial curing were placed in a sealed chamber in Fig. 1, which was then vacuumed to about 0.7 bars and filled with carbon dioxide gas to a pressure of 1 bar. The chamber was placed on a digital balance to obtain the mass curve of concrete during carbonation. The carbonation duration varied from 2 to 4 hours. A period of 96 hours was also investigated to study the effect of extreme exposure time.

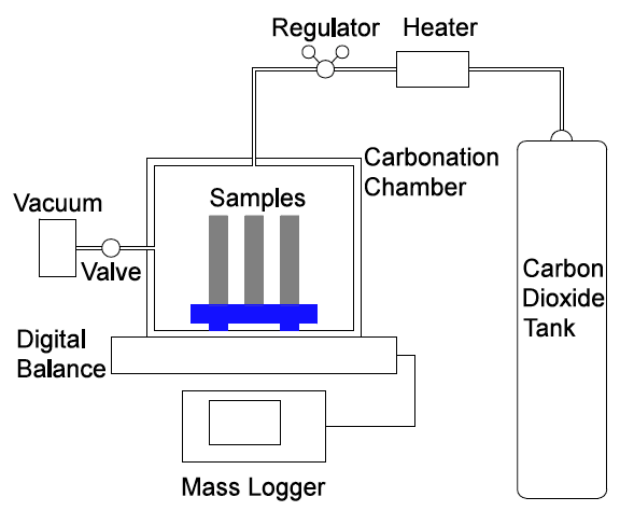

Fig. 1. Schematic of carbonation setup

TABLE II: CURING PROCEDURES

\begin{tabular}{|c|c|c|c|c|c|c|c|c|c|c|}
\hline \multirow{2}{*}{ Batch \# } & \multirow{3}{*}{ Condition } & \multicolumn{3}{|l}{ Initial curing } & \multicolumn{3}{|l|}{ Steam curing } & \multicolumn{2}{l}{ Carbonation curing } & \multirow{2}{*}{ Subsequent Hydration } \\
\cline { 3 - 12 } & & $\mathrm{RH}$ & $\mathrm{T}$ & $\mathrm{t}$ & $\mathrm{RH}$ & $\mathrm{T}$ & $\mathrm{t}$ & $\mathrm{t}$ & Water & $\mathrm{t}$ \\
\cline { 3 - 12 } & & $(\%)$ & $\left({ }^{\circ} \mathrm{C}\right)$ & (hours) & $(\%)$ & $\left({ }^{\circ} \mathrm{C}\right)$ & (hours) & (hours) & Spray $(\mathrm{g})$ & (days) \\
\hline 1 & $0 \mathrm{a}+4 \mathrm{~s}$ & - & - & 0 & $95 \pm 5$ & $75 \pm 5$ & 4 & - & - & 28 \\
\hline 2 & $4 \mathrm{a}+4 \mathrm{~s}$ & $80 \pm 5$ & $22 \pm 1$ & 4 & $95 \pm 5$ & $75 \pm 5$ & 4 & - & - & 28 \\
\hline 3 & $6 \mathrm{a}+4 \mathrm{~s}$ & $80 \pm 5$ & $22 \pm 1$ & 6 & $95 \pm 5$ & $75 \pm 5$ & 4 & - & - & 28 \\
\hline 4 & $8 \mathrm{a}+4 \mathrm{~s}$ & $80 \pm 5$ & $22 \pm 1$ & 8 & $95 \pm 5$ & $75 \pm 5$ & 4 & - & - & 28 \\
\hline 5 & $0 \mathrm{a}+4 \mathrm{c}$ & - & - & 0 & - & - & - & 4 & - & 28 \\
\hline 6 & $0 \mathrm{a}+4 \mathrm{c}^{\mathrm{w}}$ & - & - & 0 & - & - & - & 4 & $1 \pm 0.2$ & 28 \\
\hline 7 & $4 \mathrm{a}+4 \mathrm{c}$ & $50 \pm 1$ & $25 \pm 0.2$ & 4 & - & - & - & 4 & - & 28 \\
\hline 8 & $4 \mathrm{a}+4 \mathrm{c}^{\mathrm{w}}$ & $50 \pm 1$ & $25 \pm 0.2$ & 4 & - & - & - & 4 & $17 \pm 2$ & 28 \\
\hline 9 & $6 \mathrm{a}+4 \mathrm{c}$ & $50 \pm 1$ & $25 \pm 0.2$ & 6 & - & - & - & 4 & - & 28 \\
\hline 10 & $8 \mathrm{a}+4 \mathrm{c}$ & $50 \pm 1$ & $25 \pm 0.2$ & 8 & - & - & - & 4 & - & 28 \\
\hline 11 & $18 \mathrm{a}+4 \mathrm{c}$ & $50 \pm 1$ & $25 \pm 0.2$ & 18 & - & - & - & 4 & - & 28 \\
\hline 12 & $18 \mathrm{a}+4 \mathrm{c}^{\mathrm{w}}$ & $50 \pm 1$ & $25 \pm 0.2$ & 4 & - & - & - & 4 & $29 \pm 2$ & 28 \\
\hline 13 & $18 \mathrm{a}+2 \mathrm{c}$ & $50 \pm 1$ & $25 \pm 0.2$ & 18 & - & - & - & 2 & - & 28 \\
\hline 14 & $18 \mathrm{a}+96 \mathrm{c}$ & $50 \pm 1$ & $25 \pm 0.2$ & 18 & - & - & - & 96 & - & 28 \\
\hline
\end{tabular}

Note: a - Initial air curing; $\mathrm{s}$ - Steam curing; c - Carbonation; RH - Relative humidity; T - Temperature; $\mathrm{t}$ - Time; W - Water sprayed after carbonation

The effect of initial curing and carbonation curing were evaluated based on water loss and carbon uptake. To compensate for the water loss during initial curing and carbonation curing, water spray was applied to Batches 6,8 and 12 to restore the original water content and examine its effect on subsequent hydration after carbonation. The temperature, relative humidity, pressure, samples' initial and final mass, and mass of water condensed on the wall of the chamber were recorded. The best combination of initial curing and carbonation curing from slab tests was selected for 200-mm CMU production. Control concrete as reference to carbonation underwent same initial curing of $0,4,6,8$, and 18 hours in an environmental chamber at a 50\% RH and a $25^{\circ} \mathrm{C}$ for each hydration control batch.

\section{Carbon Uptake Estimation}

In order to measure the degree of carbonation, three methods were utilized for the estimation of carbon uptake: mass gain, mass curve, and thermal decomposition analysis.

Mass gain method estimates $\mathrm{CO}_{2}$ uptake in concrete by comparing mass of samples before and after carbonation (1). Carbonation-induced water loss was collected by absorbent 
paper and added to the final mass. By treating the system as a closed system, it was imperative to include the evaporated water, which was initially inside the samples prior to carbonation.

$$
\begin{array}{r}
\mathrm{CO}_{2} \text { uptake }(\%)=(\text { Final mass }+ \text { Mass of water loss }- \text { initial } \\
\text { mass }) /(\text { Mass of cement })(1)
\end{array}
$$

Mass curve method was executed by placing the carbonation setup on a digital balance, which was zeroed after vacuuming the chamber. A mass curve was recorded as mass versus time until the end of the process at which time $\mathrm{CO}_{2}$ was released and the residual mass, $\mathrm{M}$, was measured. The system was calibrated by repeating the tests using $\mathrm{CO}_{2}$-insensitive styrofoam samples of the same volume to obtain second residual mass, $\mathrm{m}$. The difference between $\mathrm{M}$ and $\mathrm{m}$ represented the $\mathrm{CO}_{2}$ uptake by concrete (2). The data obtained from mass gain and mass curve are independent from any carbon content existing before carbonation.

$$
\mathrm{CO}_{2} \text { uptake }(\%)=(\mathrm{M}-\mathrm{m}) /(\text { Mass of cement })
$$

Thermal decomposition analysis was also performed to estimate the amount of carbonates in concrete. Instead of using a classical thermogravimetry device, which allows only a few micrograms of powder, a furnace of maximum temperature of $1100^{\circ} \mathrm{C}$ was employed to test large concrete samples with mass range of 35-70 for each. Separation of paste from concrete was thus avoided. Concrete samples were heated up to $105^{\circ} \mathrm{C}, 550^{\circ} \mathrm{C}$, and $1000^{\circ} \mathrm{C}$ to quantitatively measure the evaporable water, bound water in hydration products, and carbon dioxide in carbonates respectively [6]. The mass loss between $550^{\circ} \mathrm{C}$ and $1000^{\circ} \mathrm{C}$ represents carbon uptake by carbonation (3):

$$
\mathrm{CO}_{2} \text { uptake }(\%)=\left(\text { Mass at } 550^{\circ} \mathrm{C}-\text { Mass at } 1000^{\circ} \mathrm{C}\right) /
$$

(Mass of Cement)

\section{EXPERIMENTAL RESULTS AND DISCUSSION}

\section{A. Effect of Initial Curing on Internal Water Content}

Initial curing in a controlled environment $\left(25^{\circ} \mathrm{C}\right)$ and $50 \%$ $\mathrm{RH})$ was introduced in the carbonation process to justify the water content in concrete. To explore the possibility of application of carbonation curing to CMU production, the entire curing process cannot exceed 24 hours in comparison to current steam curing practice. Therefore, the process window of initial curing is limited to $0,4,6,8$, and 18 hours at $25^{\circ} \mathrm{C}$ and $50 \% \mathrm{RH}$. The water loss curve due to initial curing up to 14 days is plotted in Fig. 2.

Percent water loss is a ratio of mass loss during initial curing in a specified time over total initial water mass. The total initial water mass is the sum of the mixing water (water-to-cement ratio of 0.4 ) and the water in wet expanded slag aggregates ( $5 \%$ of the total slag mass). The mass loss during initial curing was recorded by a digital balance over a period of 14 days at $25^{\circ} \mathrm{C}$ and $50 \% \mathrm{RH}$.

It was apparent that water loss was proportional to the duration of initial curing within 24 hours. The most significant loss occurred in first 4 hours, reaching $32 \%$. Water loss due to 6 and 8 hours initial curing was basically no different from 4 hours. However, 18 hours curing increased the water loss to $51 \%$, which was very close to that by 24 hours. Eighteen hours seemed to be the maximum possible time for initial curing and could be executed through an overnight shift. At 14 days, the water loss reached $81 \%$.

\section{B. Effect of Initial Curing on Carbonation Reaction}

Degree of carbonation is characterized by carbon uptake. Three methods are used to quantify $\mathrm{CO}_{2}$ uptake in carbonated concrete. Fig. 3 shows water loss collected from carbonation process and the carbon uptake by mass gain method (1). Two groups of data are presented in Fig. 3. First group includes the first 5 batches with constant carbonation time of 4 hours and varied initial curing of $0,4,6,8$ and 18 hours to study the effect of initial curing.

The second group involves the last three batches with constant initial curing of 18 hours and varied carbonation duration of 2, 4 and 96 hours to investigate the effect of carbonation time. Percent water loss due to exothermic carbonation curing is defined as a ratio of water collected in chamber after carbonation over total initial water mass.

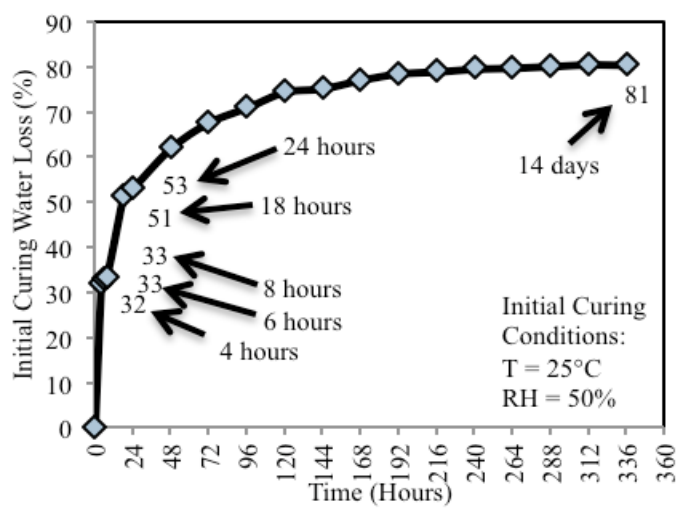

Fig. 2. Water loss due to initial curing

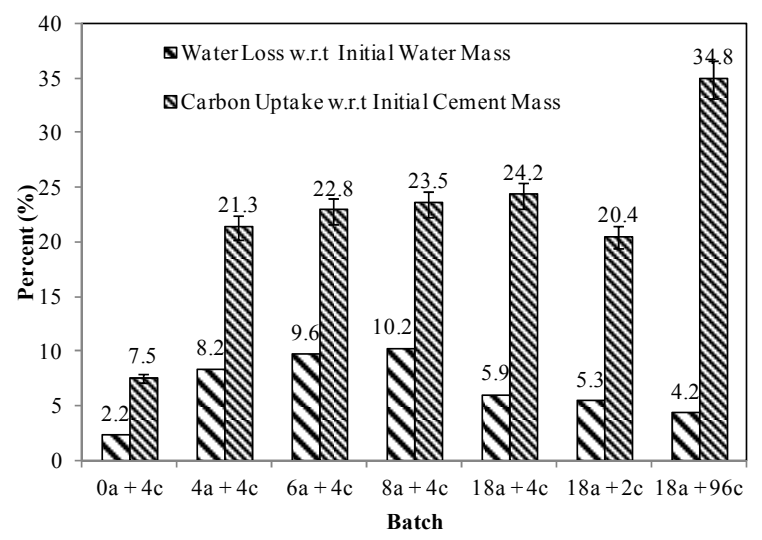

Fig. 3. Water loss due to carbonation and carbon uptake

In first group of 4-hour carbonation, immediate carbonation with no initial curing resulted in a carbon uptake of $7.5 \%$ with a carbonation water loss of $2.2 \%$. It was indicative of a low degree of reaction. After 4, 6, and 8hour initial air curing, water loss due to initial curing was of close value of $32-33 \%$. Nevertheless, their carbon uptake was different at 21.3, 22.8, and $23.5 \%$ with carbonation water loss at $8.2,9.6$, and $10.2 \%$, respectively. Obviously, initial curing reduces free water, making room for gas diffusion and calcium carbonate precipitation. Initial curing of 18 hours removed $51 \%$ free water and promoted carbon 
uptake to $24.2 \%$ with a carbonation water loss of $5.9 \%$. Prolonged initial curing is not directly beneficial to reaction efficiency.

In the second group, initial curing was fixed at 18 hours. When 2-hour carbonation was compared with 4-hour carbonation, longer carbonation evaporated more free water and promoted higher carbon uptake. In prolonged carbonation, carbon uptake by 96 hours was increased by $44 \%$ in comparison to that by 4 hours. However, water evaporation was reduced possibly due to the re-absorption of water during the 4-day process. A carbon uptake of $34.9 \%$ in 4-day carbonation represented a degree of carbonation of nearly $70 \%$, if full carbonation is considered as $100 \%$ [7]. Obviously, longer carbonation time could promote carbon uptake and enhance the carbon storage capacity of concrete.

To verify the carbon uptake by mass gain method (1), mass curves were obtained. Five batches were compared in Fig. 4 with initial curing of $0,4,6,8$ and 18 hours. During the 4-hour carbonation process, $60-70 \%$ of the reaction occurred in the first hour and $80-90 \%$ in the second hour. The third method to quantify the calcium carbonates in concrete is thermal decomposition analysis. As seen in Table III, mass loss was categorized into three components: evaporable water (up to $105^{\circ} \mathrm{C}$ ), bound water (between 105 and $550^{\circ} \mathrm{C}$ ) and carbon dioxide (between 550 and $1000^{\circ} \mathrm{C}$ ). Higher bound water indicates more hydration products. It is noted that zero initial curing has the lowest uptake but highest bound water. Other samples, as $18 \mathrm{a}+4 \mathrm{c}$, have higher uptake, which is associated with high carbonates, but low bound water content. It can be concluded that the hydration products and carbonation products cannot coexist in high quantities in one sample, or in other words, hydration products can be consumed in the carbonation reaction to produce more carbonates.

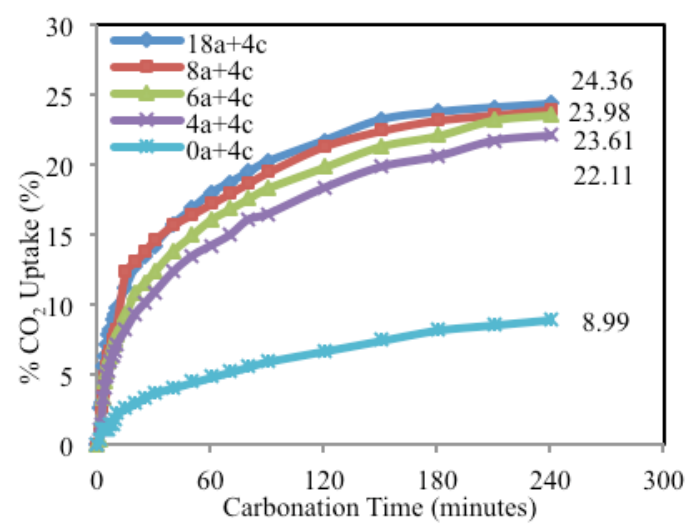

Fig. 4. Mass curves of 4-hour carbonation

However, once the water spray technique is applied to batch with 18-hour initial curing followed by 4-hour carbonation curing, both hydration and carbonation products appear to be high. Apparently, water compensation after initial curing followed by carbonation curing is effective and beneficial for subsequent hydration and overall performance. Table III also compares bound water content between carbonated and steamed concretes. After the same initial curing, the amount of hydration products is of close value in carbonated and steamed concretes, suggesting carbonation can technically replace steam to accelerate hydration. Carbon dioxide content in the last column of Table III is calculated based on total concrete mass used in thermal analysis. If the value is divided by $13 \%$, the cement content, carbon uptake is converted to cement based and comparable to the other two methods.

TABLE III: THERMAL DECOMPOSITION ANALYSIS AFTER 28 DAYS

\begin{tabular}{|c|c|c|c|c|c|c|c|}
\hline \multirow[t]{2}{*}{ Sample } & \multirow{2}{*}{$\begin{array}{c}\text { Sample } \\
\text { Mass } \\
\text { (g) }\end{array}$} & \multicolumn{2}{|c|}{$\begin{array}{c}\text { Evaporated } \\
\text { Water }^{\mathrm{a}}\end{array}$} & \multicolumn{2}{|c|}{$\begin{array}{l}\text { Combined } \\
\text { Water }^{\mathrm{b}}\end{array}$} & \multicolumn{2}{|c|}{$\mathrm{CO}_{2}{ }^{\mathrm{c}}$} \\
\hline & & M (g) & $\%{ }^{\mathrm{d}}$ & M (g) & $\%{ }^{\mathrm{d}}$ & M (g) & $0^{\mathrm{d}}$ \\
\hline $0 a+4 c$ & 47.25 & 0.90 & 1.90 & 1.66 & 3.51 & 0.55 & 1.16 \\
\hline $0 \mathrm{a}$ & .26 & 0.72 & 1.49 & 1.86 & 3.85 & 0.03 & 0.06 \\
\hline $0 \mathrm{~d}$ & 50.0 & 1.10 & 2.83 & 1.55 & 4.29 & 0.01 & 0.03 \\
\hline $4 a+4 c$ & 76.45 & 1.09 & 1.43 & 2.27 & 2.97 & 2.16 & 2.83 \\
\hline $4 a$ & 3 & 0.52 & 1 & 3 & 2 & 3 & 0.08 \\
\hline $4 a$ & 45.91 & 0.91 & 1.98 & 1.24 & 2.70 & 0.02 & 0.04 \\
\hline $6 a+4 c$ & 4 & 0.49 & 1 & 000 & 2.03 & 32 & 2.98 \\
\hline $6 a+4 s$ & 38.76 & 0.73 & 1.88 & 0.85 & 2.19 & 0.03 & 0.08 \\
\hline $6 a$ & 34.92 & 0.98 & 2.81 & 1.07 & 3.06 & 0.02 & 0.06 \\
\hline $8 a+4 c$ & 47.26 & 0.42 & 1.04 & 1.40 & 2.96 & 1.44 & 3.05 \\
\hline $8 a+4 s$ & 55.4 & 0.66 & 1.19 & 1.50 & 2.71 & 0.05 & 0.09 \\
\hline $8 a$ & 47.28 & 1.16 & 2.45 & 1.59 & 3.36 & 0.03 & 0.06 \\
\hline $18 a+4 c$ & 65.15 & 0.67 & 0.83 & 1.17 & 1.80 & 2.05 & 3.15 \\
\hline $18 \mathrm{a}+4 \mathrm{c}^{\mathrm{e}}$ & 71.14 & 0.70 & 1.97 & 1.37 & 3.65 & 1.14 & 3.20 \\
\hline $18 a+2 c$ & 50.69 & 0.47 & 0.93 & 0.86 & 1.70 & 1.43 & 2.82 \\
\hline $18 a+96 c$ & 40.57 & 0.46 & 1.13 & 0.98 & 2.42 & 1.86 & 4.58 \\
\hline $18 \mathrm{a}$ & 43.61 & 0.50 & 1.15 & 1.32 & 3.03 & 0.04 & 0.09 \\
\hline
\end{tabular}

NoTE: M - Mass; a - Difference in mass between room temperature and $105^{\circ} \mathrm{C} ; \mathrm{b}-$ Difference in mass between $105^{\circ} \mathrm{C}$ and $550^{\circ} \mathrm{C} ; \mathrm{c}-$ Difference in mass between $550^{\circ} \mathrm{C}$ and $1000^{\circ} \mathrm{C}$; $\mathrm{d}$ - Percentage of initial sample mass; e - Sprayed after carbonation

\section{Carbonation Curing of 200-mm CMU}

Process parameters are selected for 200-mm CMU production. To maximize carbon uptake within a 24-hour timeframe, it appears 18-hour initial curing followed by 4hour carbonation can reach a carbon uptake of $24 \%$ based on cement. Its carbonation degree is about $48 \%$.

Standard 200-mm CMU block was made in the laboratory and carbonated in a setup similar to that shown in Fig. 1. The fresh blocks underwent an initial curing of 18 hours at $50 \% \mathrm{RH}$ and $25^{\circ} \mathrm{C}$.

Water loss due to initial curing was about $50 \%$, very close to that observed in slab tests. The blocks were then carbonated at $0.1 \mathrm{MPa}$ gas pressure for 4 hours. Water loss due to carbonation was about $5 \%$. Carbon uptake by three block samples, at the age of 1 day, is presented in Table IV. The three methods were used in carbon estimation. In comparison, the three blocks demonstrated an uptake in the range of $23-25 \%$. These results agreed with that of the slab samples, whose uptake was approximately $24 \%$. CMU can be produced by carbonation process to replace steam and achieve superior carbon uptake capacity.

\section{Carbon Storage in Blocks and Bricks}

Reaction of cement with carbon dioxide at early age is a $\mathrm{CO}_{2}$ sequestration process. If one $200-\mathrm{mm}$ block with a mass of $15 \mathrm{~kg}$ contains $13 \%$ cement could have a $\mathrm{CO}_{2}$ uptake of $24 \%$ based on cement, one block has the capacity to store $0.47 \mathrm{~kg}$ of $\mathrm{CO}_{2}$ in a thermodynamically stable calcium carbonate form. Assuming every block or brick has the same carbon storage capacity, the projected annual production of 4.3 billion units in US market can thus consume 2 million tons of $\mathrm{CO}_{2}$ per year. 
The capacity for carbon capture and storage (CCS) in geologic formation is approximately 1 million tonnes per year per site [8]. $\mathrm{CO}_{2}$ utilization in concrete blocks and bricks production is equivalent to carbon sequestration in two geologic formation sites. The cement annual production in the United States is about 100 million tonnes with $\mathrm{CO}_{2}$ emission of 80 million tonnes. If all block and brick plants adopt carbonation curing with the same carbon uptake rate, $\mathrm{CO}_{2}$ utilization in their production lines alone could reduce carbon emission by $2.5 \%$ for cement industry.

TABLE IV: CARBON UPTAKE IN 200-MM CMU SAMPLES

\begin{tabular}{cccc} 
& \multicolumn{3}{c}{ Carbon Uptake (\%) } \\
\cline { 2 - 4 } CMU \# & Mass & Mass & Thermal \\
& Gain & Curve & analysis \\
\hline 1 & 23.8 & 24 & 23.3 \\
2 & 23.1 & 23.6 & 23.9 \\
3 & 23.6 & 23.8 & 23.5 \\
\hline
\end{tabular}

TABLE V: ENERGY CONSUMPTION AND COST ESTIMATE

\begin{tabular}{|c|c|c|c|c|}
\hline \multirow{2}{*}{ Process } & $\mathrm{P}$ & $\mathrm{V}$ & $\mathrm{P}$ & Cost \\
\cline { 2 - 5 } & $(\mathrm{kWh})$ & $\left(\mathrm{m}^{3}\right)$ & $\left(\mathrm{kWh} / \mathrm{m}^{3}\right)$ & $\left(\$ / \mathrm{m}^{3}\right)$ \\
\hline Carbonation $(18 \mathrm{a}+4 \mathrm{c})$ & 9 & 0.058 & 154.58 & 9.27 \\
\hline Carbonation & 40.5 & 0.058 & 695.61 & 41.74 \\
\hline (4a+4c) & & & & 9.84 \\
\hline Steam Curing [2] & - & 1 & 164 & 9 \\
\hline
\end{tabular}

Note: P - Power; $\mathrm{t}$ - time; V - Volume.

\section{E. The Network Operation and Cost Estimate}

To implement $\mathrm{CO}_{2}$ utilization at the vicinity of carbon sources, a network needs to be established. It shall include carbon capture, compression, transport, storage, and utilization. The network will be operational based on the assumption that large quantities of high purity and low cost carbon dioxide will be produced as regulations requiring reductions in $\mathrm{CO}_{2}$ emissions are developed and will be otherwise transported to remote area for underground geologic storage. For $\mathrm{CO}_{2}$ utilization in block production, the pressurized high purity $\mathrm{CO}_{2}$ is instead transported to block plants. The cost estimate was made by comparing carbonation curing with steam curing in Table V. It is assumed that the cost estimate starts when the pressurized gas arrives at block plants. The static carbonation process does not require additional energy except the initial air curing at $50 \% \mathrm{RH}$ and ambient temperature. For laboratory setting used in this preliminary study, the environmental chamber used consumes $2.25 \mathrm{~kW}$, but can fit up to $160 \mathrm{slab}$ samples with a total concrete volume of $0.058 \mathrm{~m}^{3}$. Accordingly, per cubic meter of concrete, initial curing by 4-hour and 18-hour consumes 155 and $696 \mathrm{kWh}$ and cost $\$ 9.27$ and $\$ 41.74$ respectively, assuming $1 \mathrm{kWh}$ of electricity costs $\$ 0.06$. Energy consumption in atmospheric steam curing is well studied. It is approximately $164 \mathrm{kWh}$ for cubic meter concrete [2] and costs $\$ 9.84$. With reference to steam, the cost by 4-hour initial curing is comparable but the cost by 18-hour initial curing is too high. In order to reduce the cost without compromising the superior performance, the initial curing duration must be modified while maintaining more than $50 \%$ water loss. Technically, an environment for initial curing at 50\% RH and ambient temperature can be easily created on production site with no need of an environmental chamber. There is room to reduce the energy consumption in carbonation by using different initial curing and eliminating vacuum. While the industrial steam curing has been optimized in the last 30 years for mass production, the cost of the network operation for carbonation should also be analyzed and optimized to make the system economically feasible and sustainable.

\section{REFERENCES}

[1] Freedonia Group, "Brick and block demand to reach 12.4 billion units, \$8 billion by 2014," Journal of Concrete Products, Freedonia Group Study, Issue 2652, 2010.

[2] K. Kawai and T. Sugiyama, "Inventory data and case studies for environmental performance evaluation of concrete structures," Journal of Advanced Concrete Technology, pp. 435-456, 2005.

[3] V. Rostami, Y. Shao, and A. Boyd, "Durability of concrete pipes subjected to combined steam and carbonation curing," Construction and Building Materials, vol. 25, pp. 3345-3355, 2011.

[4] Y. Shao, M. S. Mirza, and X. Wu, " $\mathrm{CO}_{2}$ sequestration using calciumsilicate concrete," Canadian Journal of Civil Engineering, vol. 33, pp. 776-784, 2006.

[5] Standard Test Methods for Sampling and Testing Concrete Masonry Units and Related Units, ASTM International, 2004.

[6] C. J. Goodbrake, "Reaction of beta-dicalcium silicate and tricalcium silicate with carbon dioxide and water vapor," Journal of the American Ceramic Society, pp. 168-171, 1979.

[7] H. H. Steinour, "Some effects of carbon dioxide on mortars and concrete - a discussion," Journal of American Concrete Institute, vol. 55, no. 2, pp. 905-907, 1959.

[8] IPCC, "IPCC Special Report on Carbon Dioxide Capture and Storage", Cambridge, 2005.

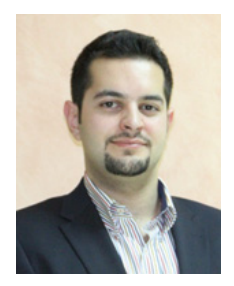

Hilal H. El-Hassan completed his Ph.D. degree at McGill University, Montreal, Canada in 2012. He had received his BSc. and $\mathrm{MSc}$. degrees from the University of Balamand, Lebanon, in 2008 and 2010, respectively.

He currently is an assistant professor of Civil Engineering at the American University in Dubai in the United Arab Emirates. He previously worked as a Teaching at McGill University in the Department of Civil Engineering and Applied Mechanics. Apart from his academic experience, Dr. El-Hassan has gained industrial experience working in project planning and construction with Building Plus Contracting and Oger in Lebanon and UAE. His major field of study covers vast areas of concrete design and building materials, majorly focusing on cement and concrete development. His expertise also lies in the domain of carbon capture and storage (CCS) along with microstructure analysis of cement and concrete. The second paragraph uses the pronoun of the person (he or she) and not the author's last name. He has several publications and conference proceedings in the area of concrete carbonation.

Dr. El-Hassan is a member of the American Concrete Institute (ACI). He received the McGill Excellence Doctoral Award, and Provost Award for the years of 2010-2012. He also received the Engineering Excellence Award for Graduate and Undergraduate students at University of Balamand for the years 2008 and 2010, respectively.

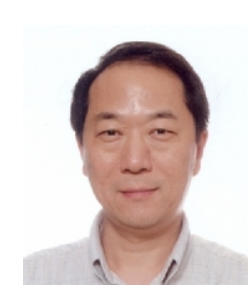

Yixin Shao completed his Ph.D. degree at Northwestern University, Evanston, IL in 1995. He had received his BSc. and MSc. degrees from the Tongji University, China, in 1982 and 1984, respectively.

He currently occupies the position of Associate Chair and Associate Professor of Civil Engineering at McGill University, Montreal, Canada. His research interests include carbonation curing of concrete, utilization of wastes, fiber-reinforced cement-based composites, fiber-reinforced plastic composites, utilization of wastes, environment friendly building materials, durability, and Moiré interferometry for stress and strain analysis fiber-reinforced polymers. $\mathrm{He}$ has numerous publications and conference proceedings in areas covering concrete carbonation as well as composite material design.

Professor Shao is a fellow member of the American Concrete Institute (FACI). He received Engineering Award for Outstanding Teaching in 2000 and the Canada Foundation Award for Innovative Research in 1998. 